\title{
A survey of specialist perinatal mental health services in England
}

\author{
AIMS AND METHOD \\ To survey current specialist \\ perinatal psychiatric provisions \\ and opinion about these services \\ in England. A brief semi-structured \\ confidential questionnaire was \\ circulated to the lead clinician or \\ manager responsible for perinatal \\ services of the 78 mental health \\ trusts in England.
}

\author{
RESULTS \\ Fifty-seven trusts (73\%) responded. In 26 \\ trusts $(46 \%)$, availability of either specia- \\ list in-patient facilities and/or intensive \\ home treatment facilities were reported. \\ In only 13 trusts (23\%) was there evidence \\ of provision of services covering both in- \\ patient and community components. The \\ number of mother and baby units or their \\ equivalents has reduced in the past
}

decade. The services were generally considered to be inadequate nationwide and opinion remains divided about the best approach for providing them.

\section{CLINICAL IMPLICATIONS}

There is a need for a recommendation of a national standard provision of perinatal services by mental health trusts.
Reports show that suicides in women with psychiatric disorders are a leading cause of maternal deaths in England and psychiatric disorders continue to impact adversely on pregnancy, mothers, infants and society at large (Brockington, 1998; Royal College of Psychiatrists, 2000; Department of Health, 2001; Evans et al, 2001). Concerns about inadequate specialist perinatal psychiatric care facilities in these reports led to recommendations that they should be commissioned.

There is a dearth of information on currently available services. Prettyman \& Friedman (1991) in a postal survey of 201 health authorities in England and Wales found that about a fifth had dedicated admission facilities for mothers with mental illness and their babies and only a few offered specialist consultations or had specialist community teams. Opinions vary about the best approach for the provision of these services: ranging from a traditional integrative approach that involves strengthening existing generic community mental health teams and other services, to stand-alone specialist services which specifically address the needs of perinatal women (Perinatal Specialist Interest Group, Royal College of Psychiatrists, 2003).

We present a recent survey of specialised perinatal psychiatric services and views of professionals working in this field in England.

\section{Method}

The study was a two-stage postal survey carried out between January and June 2003. In stage 1, medical directors of the 78 relevant mental health trusts in England were contacted and requested to provide contact details of the lead clinician or manager for perinatal services, or in the absence of a designated person, the clinical director of working age adult services. The named persons were then contacted and requested to fill in a confidential questionnaire in the second stage. A telephone interview option was provided. Repeated contacts were made to non-responding trusts and informal contacts were used to identify services when necessary. In trusts with more than one site and different levels of service provisions, the site with the most comprehensive service was chosen. We enquired about provisions of documents for perinatal services, professional staff involved, mother and baby units, teams and views about the service provisions.

\section{Results}

Out of 78 trusts contacted, 66 responded to stage 1 contacts, while 57 responded to stage 2 contacts, giving a final response rate of $73 \%$. The responses obtained were through 48 returned questionnaires, 5 letters and 4 telephone interviews. The findings are shown in Table 1. Of the responding personnel, $65 \%$ were clinicians, usually consultants.

The provision of documents and protocols was the most common service provided by the responding trusts: provided by 33 trusts (58\%). The most common were guidelines for management of perinatal disorders such as depression, for use in primary care; followed by mother and baby admission policies; and less commonly perinatal care strategy documents (Table 1). These documents were considered outdated/inadequate in 16 of the trusts $(48 \%)$ that had them.

In 20 of the trusts (35\%) there was a perinatal multidisciplinary team; 6 had no community staff. Liaison psychiatrists constituted $90 \%$ of the consultants involved in the services, providing on average 4 sessions per week; 2 trusts had a full-time perinatal psychiatrist. Specialist registrars were the trainees most involved in the services but senior house officers provided more sessions. Eleven trusts had 1 or more full-time community psychiatric nurse (CPN) in their service; the average number of CPNs per team was 2 including part-time CPNs. The number of social workers and psychologists were even less (Table 1).

A total of 21 trusts (37\%) had facilities for admissions of mother and babies, with two-thirds of the facilities being in dedicated units and the rest being designated beds in an open ward. There were 2 units 
Table 1. Specialist perinatal services provisions

original

papers

\begin{tabular}{|c|c|}
\hline & $\begin{array}{l}\text { No. of trusts }(\%) \\
\quad(\text { Total }=57)\end{array}$ \\
\hline \multicolumn{2}{|l|}{ Documents and protocols: } \\
\hline 1. Perinatal services strategy document & $19(33)$ \\
\hline $\begin{array}{l}\text { 2. Treatment protocol for perinatal } \\
\text { disorders }\end{array}$ & $29(51)$ \\
\hline 3. Mother and baby admission policy & $22(39)$ \\
\hline \multicolumn{2}{|l|}{ Personnel: } \\
\hline $\begin{array}{l}\text { 1. Designated perinatal multidisciplinary } \\
\text { teams }\end{array}$ & $20(35)$ \\
\hline \multicolumn{2}{|l|}{$\begin{array}{l}\text { 2. Clinical session (at least } 1 \text { per week) } \\
\text { in perinatal psychiatry }\end{array}$} \\
\hline $\begin{array}{l}\text { 1. Consultant liaison psychiatrists } \\
\text { (special interest) }\end{array}$ & $22(39)$ \\
\hline $\begin{array}{l}\text { 2. Consultant general psychiatrists } \\
\text { (special interest) }\end{array}$ & $3(5)$ \\
\hline 3. Training grade psychiatrists & $15(26)$ \\
\hline 4. Staff grades/associate specialists & $7(12)$ \\
\hline 3. In-patient nurses (full-time) & $14(25)$ \\
\hline \multicolumn{2}{|l|}{ 4. Community psychiatric nurses (CPNs) } \\
\hline 1. One or more full-time CPN & $11(19)$ \\
\hline 2. One or more part-time CPN & $6(11)$ \\
\hline 5. Social workers (full-time or sessional) & $10(18)$ \\
\hline $\begin{array}{l}\text { 6. Psychologists/trainee (full-time } \\
\text { or sessional) }\end{array}$ & $9(16)$ \\
\hline 7. Occupational therapists & $7(12)$ \\
\hline 8. Others, e.g. nursery nurses & $19(33)$ \\
\hline \multicolumn{2}{|l|}{ Facilities/services: } \\
\hline $\begin{array}{l}\text { 1. Admission facilities for mothers } \\
\text { and babies }\end{array}$ & $21(37)$ \\
\hline 1. Dedicated units & $14(25)$ \\
\hline 2. Designated beds in open ward & $7(12)$ \\
\hline 2. Day hospital & $2(4)$ \\
\hline 3. Intensive home treatment & $5 \quad(9)$ \\
\hline $\begin{array}{l}\text { 4. Specific service for obstetric ward } \\
\text { referrals }\end{array}$ & $17(30)$ \\
\hline 5. Obstetric liaison clinic & $14(25)$ \\
\hline 1. With midwives/others & $8(14)$ \\
\hline 2. Stand-alone clinic & $6(11)$ \\
\hline \multicolumn{2}{|l|}{ Other specialist services: } \\
\hline 1. Perinatal primary care liaison team & $12(21)$ \\
\hline 2. Prenatal counselling clinic & $12(21)$ \\
\hline 3. Parenting skills assessment clinic & $3(5)$ \\
\hline 4. Substance misuse services & $19(33)$ \\
\hline 5. Service for teenage mothers & $3(5)$ \\
\hline
\end{tabular}

with 10 beds, 3 with $5-8$ beds and 6 units with $3-4$ beds, with the rest having 2 beds. Ninety-two per cent of the units were under the care of a liaison psychiatrist. The available number of beds was regarded as inadequate in 6 of the trusts, while 3 trusts reported under-used beds as a result of staffing shortages. Only a few trusts had intensive home care or day hospital services, an area specifically identified to be inadequate by many responders. There were teams for obstetric ward referrals in 17 trusts $(30 \%)$ while obstetric liaison clinics or equivalent were provided in 14 trusts (25\%), often with midwives. Some other specific community services were reported (Table 1).

Overall, there was evidence in only 13 trusts (23\%) of provision of the full range of services from in-patient
Table 2. Summary of overall facilities

\begin{tabular}{|c|c|}
\hline Facilities & $\begin{array}{l}\text { No. of trusts }(\% \\
\quad(\text { Total }=57)\end{array}$ \\
\hline $\begin{array}{l}\text { 1. In-patient facility } /{ }^{*} \text { intensive home } \\
\text { treatment }\end{array}$ & $26(46)$ \\
\hline $\begin{array}{l}\text { 2. Community teams/follow-up service/ } \\
* \text { day hospital }\end{array}$ & $19(33)$ \\
\hline 3. Service for ward referrals/liaison clinics & $17(30)$ \\
\hline 4. Combination of 1,2 and 3 & $13(23)$ \\
\hline $\begin{array}{l}\text { 5. None of } 1,2 \text { and } 3 \text { but has protocols } \\
\text { and policies and/or specific } \\
\text { arrangements with nearby trusts }\end{array}$ & $16(26)$ \\
\hline $\begin{array}{l}\text { 6. No provisions or any evidence } \\
\text { of specific arrangement }\end{array}$ & $15(26)$ \\
\hline
\end{tabular}

and/or intensive home treatment to obstetrics ward and liaison clinic services (Table 2). However, $46 \%$ of trusts have either an in-patient service or an intensive home treatment service. The remaining trusts had no specific perinatal facilities; about half of those rely on arrangements with neighbouring trusts for admission beds, including 3 trusts that use beds in the private sector. A quarter of all the responding trusts thus reported no services or any specific arrangements.

Problems identified by responders include the following. The need for more community nurses, social workers and psychologists (in that order) were commonly identified inadequacies. Five trusts identified inadequate 'primary care provisions' for the community care of perinatal women, while 4 trusts relate their main problem to having too large a geographical area and a small number of patients needing specialist services; the same reason was given by 2 trusts for not providing day hospital services. Other problems reported included lack of coordination between different specialist services and lack of appropriate supported housing for mothers that can also cater for their babies after discharge.

Views on the need for specialist perinatal mental health services were expressed by $53 \%$ of responders. The majority of opinion supported continuing provision of specialist services, with academics tending to express this view more strongly than proponents of generic services who were mostly medical and/or clinical directors. Most responders considered their current services to be inadequate. Ten trusts reported specifically that perinatal services were not considered a priority by their primary care trusts, as services had stopped, were about to be stopped or had been recently reduced for cost reasons. Only 3 trusts reported specific future developmental plans.

\section{Discussion}

This survey reveals that less than half of the mental health trusts in England provide specialist perinatal services, of which only a few provide all components of 
the required services. A large number of trusts have no specialist services while a significant number rely on arrangements with nearby trusts, mainly for provision of in-patient beds. Despite the confidential nature of the survey and repeated enquiries, a quarter of the trusts contacted did not respond. The high level of nonprovision of specialist perinatal services by the responding trust and our ascertainment process suggest that the non-responding trusts do not provide these services.

Our findings show a reduction in the number of dedicated in-patient units for perinatal women in England from 35, since the Prettyman \& Friedman (1991) survey, to 21 in this survey. The provision of such units is considered expensive and segregative (Barnett \& Morgan, 1996). The shift in focus of psychiatric care to the community may be another important factor. However, appropriate alternatives to in-patient admission for perinatal women are lacking. In this survey, the numbers of community staff were small, specialist perinatal home treatment services were provided by only 5 trusts and only 2 had specialist day hospitals.

Liaison psychiatrists are now more involved in provision of these services compared with over a decade ago (Prettyman \& Friedman, 1991). They provide the necessary leadership thrust and supervise the trainee doctors for these services. Reports that some trusts have recently reduced or stopped their services underlie the prevalent view that provision of perinatal services is not considered to be a priority by primary care trusts and that it has generally suffered since the 1999 trusts' restructuring.

In conclusion, the majority of mental health trusts in England are currently not providing specialist perinatal services. It appears that most perinatal women with mental disorders are being served by generic menta health services which have proved inadequate (Department of Health, 2001). There is a continuing difference of opinion about the best approach for providing these services. A lack of a clear national approach has raised fears that these services are 'in a no man's land' in the current government policies (Perinatal Specialist Interest Group, Royal College of Psychiatrists, 2003). There is a need for a national minimum standard.

original

papers

\section{Declaration of interest}

None.

\section{Acknowledgement}

We thank all our professional colleagues for their time in completing the questionnaires.

\section{References}

BARNETT, B. \& MORGAN. M. (1996) Postpartum psychiatric disorders: who should be admitted and to which hospital? Australian and New Zealand Journal of Psychiatry, 30, 709-714

BROCKINGTON, I. (1998) Puerperal disorders. Advances in Psychiatric Treatment, 4, 312-319.

DEPARTMENT OF HEALTH (2001) Why Mothers Die: Reports on Confidential Enquiry into Maternal Deaths, 19971999. London: Department of Health

EVANS, J., HERON, J., FRANCOMB, $\mathrm{H}$ et al (2001) Cohort study of depressed mood during pregnancy and childbirth. BMJ, 323, 257-260.

*Olufemi Oluwatayo Specialist Registrar, Brandon Mental Health Unit, Leicester General Hospital, Gwendolen Road, Leicester LE5 4PQ Trevor Friedman Consultant Liaison Psychiatrist, Brandon Mental Health Unit, Leicester General Hospital
PERINATAL SPECIALINTEREST GROUP

(2003) Report of the Section of Liaison Psychiatry on behalf of the Perinatal Special Interest Group of the Royal College of Psychiatrists. London: Royal College of

Psychiatrists.

PRETTYMAN, R. \& FRIEDMAN, T. (1991) Care of women with puerperal and psychiatric disorders in England and Wales. BMJ, 302, 1245-1246.

ROYAL COLLEGE OF PSYCHIATRISTS

(2000) Perinatal Maternal Menta

Health Services. Council Report

CR88. London: Royal College of Psychiatrists. 